\title{
Low-grade cribriform cystadenocarcinoma of the palatal gland: A case report
}

\author{
SHOICHIRO KOKABU $^{1,2}$, JUNYA NOJIMA ${ }^{1}$, HIDEKAZU KAYANO ${ }^{3}$ and TESTUYA YODA ${ }^{1}$ \\ ${ }^{1}$ Department of Oral and Maxillofacial Surgery, Faculty of Medicine, Saitama Medical University, Moroyama, \\ Saitama 350-0495; ${ }^{2}$ Division of Molecular Signaling and Biochemistry, Department of Health Promotion, \\ Kyushu Dental University, Kitakyusyushi, Fukuoka 803-8580; ${ }^{3}$ Department of Pathology, \\ Faculty of Medicine, Saitama Medical University, Moroyama, Saitama 350-0495, Japan
}

Received October 6, 2014; Accepted June 25, 2015

DOI: $10.3892 / 01.2015 .3528$

\begin{abstract}
Low-grade cribriform cystadenocarcinoma (LGCCC) is a malignant salivary gland tumor. LGCCC occurs rarely, with the parotid gland being the most commonly afflicted site. Few cases arise in other sites. The present study reports a case of LGCCC that occurred at the palatal gland of the hard palate. A 56-year-old female was referred to Saitama Medical University Hospital (Moroyama, Saitama, Japan) due to an intraoral mass. Since cytological examination and biopsy led to a diagnosis favoring a neoplasm, but with uncertain malignant potential, the tumor was resected with a safe surgical margin. The specimen was thoroughly examined. Microscopically, there was a well-demarcated, unilocular cyst with the lumen lined by tumor cells. The tumor cells were arranged in tubular, cribriform and solid structures in the area of the intracystic mass lesions. Nuclear atypia was inconspicuous, although mitotic figures were observed throughout the tumor. Neither local nor perineural invasion was present. On immunohistochemistry, the tumor cells were diffusely positive for S-100 protein. Myoepithelial markers, calponin and p63, highlighted the cells rimming the cystic mass. The final histopathological diagnosis was of LGCCC. The tumor was completely resected. At 1 year post-resection, the patient exhibited no recurrence or distant metastasis. LGCCC is regarded as clinically indolent. However, there is little literature available to aid with prognosis prediction
\end{abstract}

Correspondence to: Dr Shoichiro Kokabu, Department of Oral and Maxillofacial Surgery, Faculty of Medicine, Saitama Medical University, 38 Morohongo, Moroyama, Iruma, Saitama 350-0495, Japan

E-mail: r14kokabu@fa.kyu-dent.ac.jp

Abbreviations: LGCCC, low-grade cribriform cystadenocarcinoma; PCVACC, papillary cystic variant of acinic cell carcinoma

Key words: palatal gland, salivary gland tumor, low-grade cribriform cystadenocarcinoma, salivary duct carcinoma due to the rarity of LGCCC cases. Thus, greater experience and longer follow-up periods are necessary to find the optimal/curative treatment for patients with LGCCC and to clarify the pathophysiology.

\section{Introduction}

Salivary gland tumors produce a variety of histological patterns making tumor classification difficult (1).

Low-grade cribriform cystadenocarcinoma (LGCCC) is a malignant salivary gland originally reported as a variant of salivary duct carcinoma (2). However, LGCCC differs from typical salivary duct carcinomas with respect to the growth pattern, a lack of evident nuclear atypia, invasiveness to the surrounding tissues, and regional lymph node metastasis $(2,3)$. Thus, the 2005 World Health Organization classification considers this neoplasm to be a variant of cystadenocarcinoma, mainly due to its cystic morphology, since no definite association has been found between salivary duct carcinoma and LGCCC (1). In this classification system, LGCCC is defined by its histological similarity to breast atypical ductal hyperplasia or low-grade ductal carcinoma in situ (1).

LGCCC is extremely rare and thus, the incidence rate of LGCCC remains unknown. The parotid gland is the most commonly involved site. Few cases arise at other sites, such as the submandibular gland and palate (2-7). The present study reports a case of LGCCC that occurred at the palatal gland of the hard palate. Written informed consent was obtained from the patient.

\section{Case report}

A 56-year-old female was referred to Saitama Medical University Hospital (Moroyama, Saitama, Japan) from a local dentist in July 2013 due to the presence of an intraoral mass. The patient had noticed this mass 1 month previously.

The mass, measuring 20x18 $\mathrm{mm}$ in diameter, was located on the right side of the hard palate (Fig. 1A). The mass was soft and non-tender, and did not adhere to the oral mucosa. The surface showed normal mucosa. X-ray examination revealed no abnormality of the bone. Computed tomography 

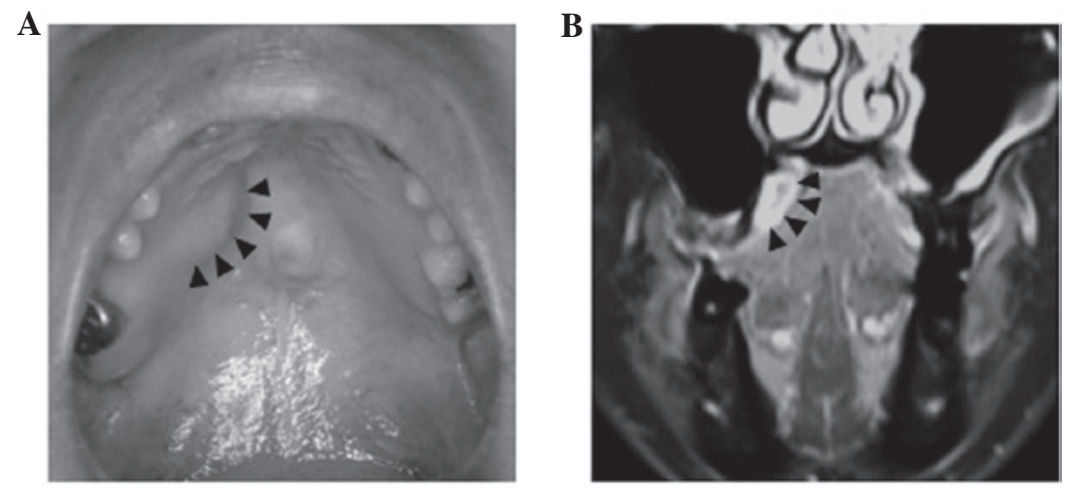

Figure 1. Intraoral findings at the first visit and magnetic resonance imaging view. (A) The mass was located on the right side of the hard palate. The surface showed normal mucosa (arrowheads). (B) Magnetic resonance imaging showed a high-intensity cystic mass with internal fluid on T1-weighted imaging of the right palatal region (arrowheads).
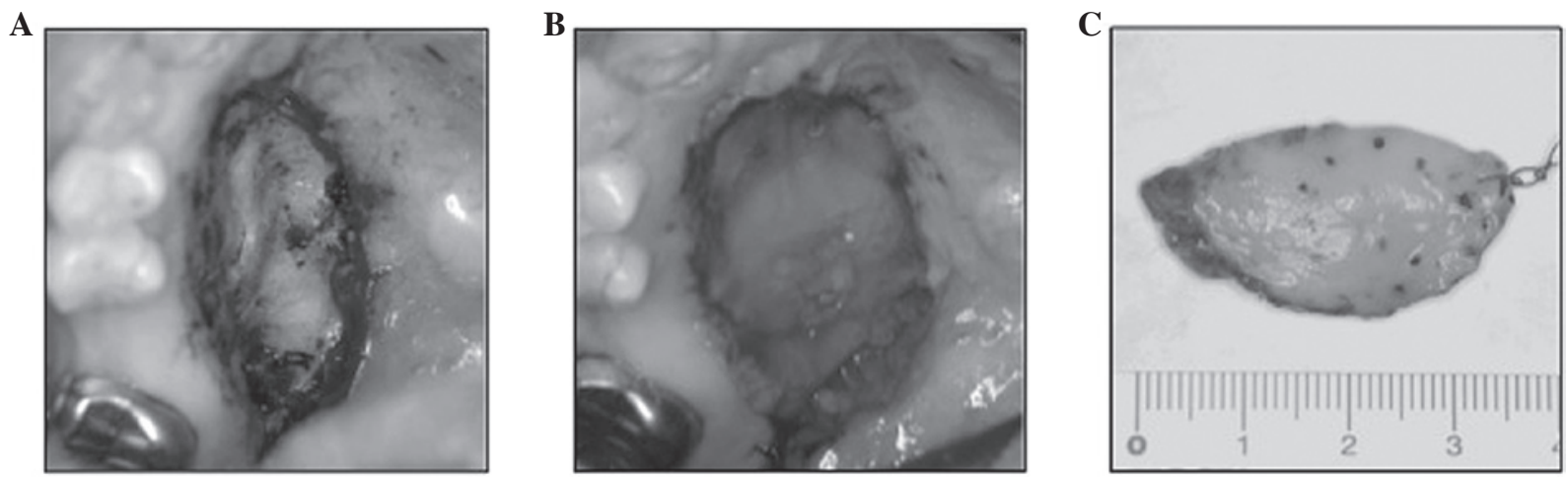

Figure 2. Tumor resection. (A) The tumor was resected with a safe surgical margin and dissected from the adjacent palatal bone. (B) The palatal bone was covered with a poly-glycolic acid sheet and fibrin. (C) Excised tissue, including the tumor.

could not detect any abnormalities at the palatal region, probably as the mass was too small to detect. Magnetic resonance imaging showed a high-intensity cystic mass with fluid internally on T1-weighted imaging of the right palatal region (Fig. 1B). Fine-needle aspiration (FNA) revealed that this mass contained brown-yellow fluid. Cytological examination and biopsy led to a diagnosis favoring a neoplasm, but with uncertain malignant potential. Thus, the tumor was resected with a safe surgical margin. The tumor was easily dissected from the adjacent palatal bone (Fig. 2A). Subsequent to resection, the palatal bone was covered with a poly-glycolic acid sheet and fibrin (Fig. 2B).

The surgical specimen measured $3.5 \mathrm{~cm}$ at its largest diameter (Fig. 2C). The specimen was thoroughly examined. Microscopically, there was a well-demarcated, unilocular cyst with the lumen lined by tumor cells (Fig. 3A). The tumor cells were arranged in tubular, cribriform and solid structures in the area of the intracystic mass lesions (Fig. 3B-D). Nuclear atypia was inconspicuous, although mitotic figures were observed throughout the tumor. Neither local nor perineural invasion was present. On immunohistochemistry, the tumor cells were diffusely positive for S-100 protein (Fig. 3E). Myoepithelial markers, calponin and p63, highlighted the cells rimming the cystic mass, confirming the intraductal nature of tumor (Fig. 3F). The final histopathological diagnosis was of LGCCC.
The tumor was completely resected, and 1 year later, the patient exhibited no recurrence or distant metastasis.

\section{Discussion}

To date, there have been 12 published studies reporting a total of 39 cases of LGCCC (2-5,7-14). Characteristics of the reported cases together with the present case are summarized in Table I. From the literature, it is evident that LGCCC commonly occurs among older patients (median age, 60.73 years), with a female predominance (females:males, 23:16; gender was unreported in 1 case). A total of 36 tumors (90\%) arose from the parotid glands, including the intraparotid lymph node and accessory parotids. The remaining 4 cases arose in the palate and submandibular gland, suggesting that the present case, which also occurred in the palate, is an rare event. LGCCC is regarded as a low-grade malignant tumor with indolent clinical behavior. Due to this clinical indolence, the majority of cases were treated with tumor excision without radiotherapy. Among the cases with follow-up data available, no patient experienced recurrence of the tumor or succumbed due to the tumor (Table I) (7).

The differential diagnosis of LGCCC includes several salivary tumors, such as papillary cystic variant of acinic cell carcinoma (PCVACC) and other variants of cystadenocarcinoma (1). Indeed, in the present case, when five specialists of 

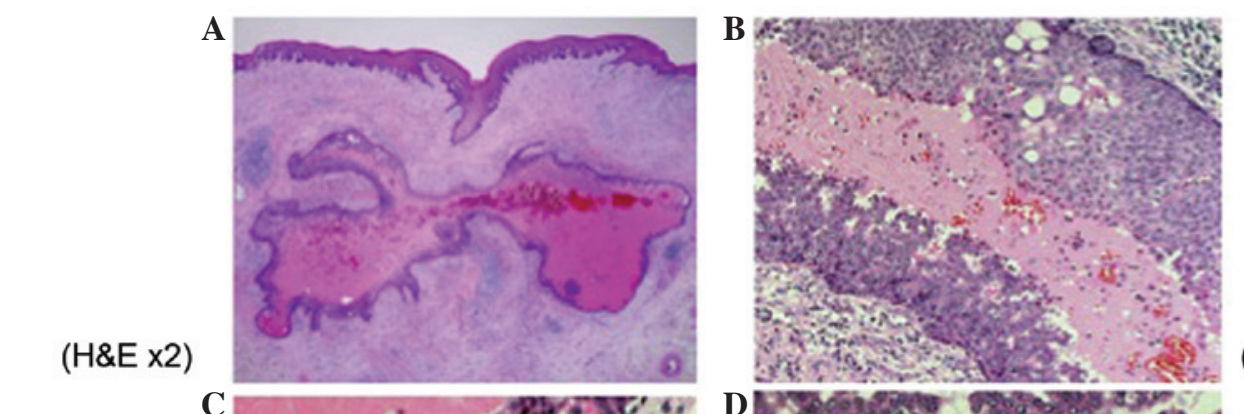

(H\&E x20)
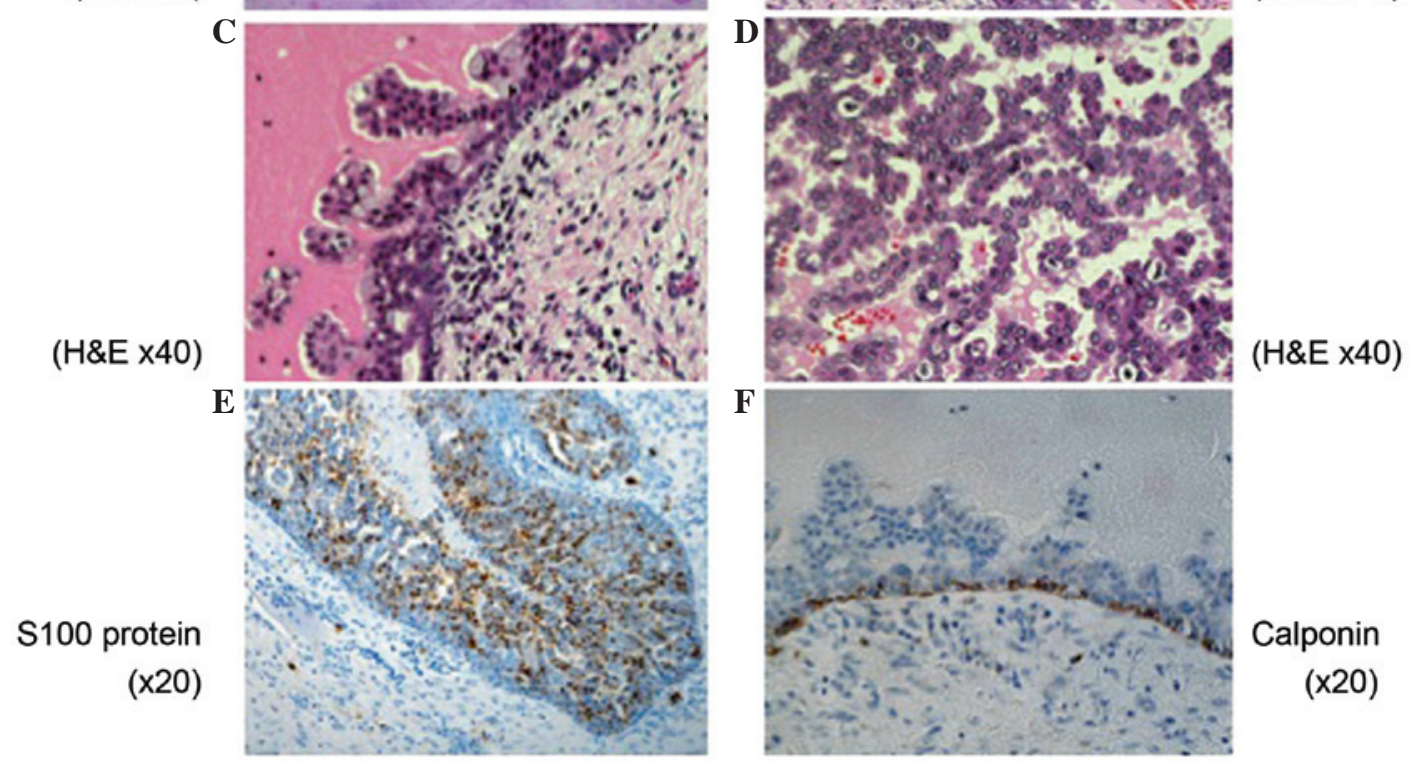

Calponin

(x20)

Figure 3. Histopathological findings. (A) Encapsulated tissues consisting of single cyst. The cystic lumens were lined by the tumor cells [hematoxylin and eosin (HE) staining; original magnification, $\mathrm{x} 2]$. (B-D) The tumor cells were arranged in (B and C) tubular, solid and (D) cribriform structures [HE staining; original magnification, (B and C) x20 and (D) x40]. (E and F) By immunohistochemistry, the tumor cells were diffusely positive for (E) S-100 protein and (F) the myoepithelial marker, calponin, highlighted the cells rimming the cystic mass (original magnification, $\mathrm{x} 20$ ).

salivary gland pathology were consulted, they listed PCVACC as a differential diagnosis for LGCCC. PCVACC contains vacuolated cells similar to the microvacuolated cells of LGCCC. However, the vacuoles of LGCCC are smaller, refractile and associated with a yellow-brown pigment, while areas with periodic acid Schiff-positive diastase-resistant fine cytoplasmic granules are found in PCVACC $(1,15)$. In contrast to PCVACC $(1,16)$, LGCCC also strongly expresses S-100 protein, as observed in the present case (Fig. 3E). Conventional cystadenocarcinoma differs from LGCCC by the lack of intraductal proliferation, golden brown pigment, solid cellular foci, and an overall resemblance to atypical hyperplasia or carcinoma in situ of the breast. Cystadenocarcinoma tends to be an invasive tumor, whereas LGCCC is usually confined to the cystic wall $(1,15)$.

Necrosis of the central region of the proliferating tumor nests frequently occurs $(1,17)$. Necrosis is usually uncommon in LGCCC, although in the present case, the central portion of the tumor exhibited necrosis. Biopsy or FNA, which was performed in the present study, may affect the tumor, and necrosis may occur in a tumor region.

The variability and histological complexity of salivary gland tumors does not allow an easy diagnosis $(1,18)$. The variations appear to be based on the multi-differential potentiality of the salivary gland cells and their stem cells (19-21). Indeed, in the present case, the formation of a final diagnosis was difficult. Although the morphological and immunohistochemical features are comparatively well investigated, little else is known about the genetics or pathogenesis of these tumors (22). Recently, the association between the rearrangement of genes such as PLAG1 and HMGA2 with the prognosis of LGCCC have been investigated (22). Such studies may confer novel insights with regard to an understanding of LGCCC and the establishment of novel methods to diagnose the disease.

In conclusion, the present study reported a LGCCC that arose in the hard palate. Although LGCCC is regarded as clinically indolent, there is limited literature on prognosis prediction, since LGCCCs, and particularly those that arise in the palatal salivary gland, are rare tumors. Moreover, several cases have been reported of more aggressive and invasive carcinomas that are presumed to arise in LGCCC $(4,6,22)$. Thus, greater experience and longer follow-periods are necessary to find an optimal/curative treatment for LGCCC and to clarify the pathophysiology.

\section{Acknowledgements}

The authors would like to thank the members of the Department of Oral and Maxillofacial Surgery, Faculty of Medicine, Saitama Medical University for providing valuable comments and discussions. The authors are particularly grateful to Dr Shojiro Morinaga (Kitasato University) for supplying valuable suggestions and to Dr William N. Addison (Harvard 
Table I. Characteristics of the reported cases and the present case of low-grade cribriform cystadenocarcinoma.

\begin{tabular}{|c|c|c|c|c|c|c|c|}
\hline Case & First author, year (ref.) & Age, years & Gender & Location & Size, $\mathrm{cm}$ & Treatment & Follow-up, months \\
\hline 1 & Delgado et al, 1996 (2) & 58 & M & Parotid & 1.0 & Parotidectomy & Not mentioned \\
\hline 2 & & 62 & $\mathrm{~F}$ & Parotid & 0.7 & Parotidectomy & Not mentioned \\
\hline 3 & & 32 & $\mathrm{~F}$ & Parotid & 1.1 & $\begin{array}{l}\text { Parotidectomy, } \\
\text { Radiotherapy }\end{array}$ & NED, 144 \\
\hline 4 & & 63 & M & Parotid & 1.3 & Parotidectomy & NED, 132 \\
\hline 5 & & 74 & M & Parotid & 1.8 & Parotidectomy & NED, 72 \\
\hline 6 & & 56 & $\mathrm{~F}$ & Parotid & 1.0 & Parotidectomy & NED, 24 \\
\hline 7 & & 42 & M & Parotid & 1.2 & Parotidectomy & NED, 24 \\
\hline 8 & & 69 & $\mathrm{~F}$ & Parotid & 4.0 & Parotidectomy & NED, 24 \\
\hline 9 & & 69 & M & Parotid & 0.9 & Parotidectomy & Not mentioned \\
\hline 10 & & 52 & $\mathrm{~F}$ & Parotid & 0.8 & $\begin{array}{l}\text { Parotidectomy, } \\
\text { Radiotherapy }\end{array}$ & NED, 9 \\
\hline 11 & Tatemoto et al, 1996 (8) & 58 & $\mathrm{~F}$ & Palate & 1.0 & Not mention & NED, 30 \\
\hline 12 & $\begin{array}{l}\text { Brandwein-Gensler } \\
\quad \text { et al, } 2004 \text { (3) }\end{array}$ & 62 & $\mathrm{~F}$ & $\begin{array}{c}15 \text { parotid, } \\
1 \text { submandibular } \\
\text { gland }\end{array}$ & N/A & Not mentioned & NED, 12 \\
\hline 13 & & 82 & M & & & & NED, 44 \\
\hline 14 & & 78 & $\mathrm{~F}$ & & & & NED, 17 \\
\hline 15 & & 72 & $\mathrm{~F}$ & & & & NED, 108 \\
\hline 16 & & 93 & $\mathrm{~F}$ & & & & NED, 24 \\
\hline 17 & & 64 & $\mathrm{~F}$ & & & & NED, 30 \\
\hline 18 & & 66 & $\mathrm{U}$ & & & & NED, 62 \\
\hline 19 & & 57 & $\mathrm{~F}$ & & & & NED, 33 \\
\hline 20 & & 63 & M & & & & Not mentioned \\
\hline 21 & & 57 & $\mathrm{~F}$ & & & & NED, 30 \\
\hline 22 & & 63 & $\mathrm{~F}$ & & & & Not mentioned \\
\hline 23 & & 64 & M & & & & NED, 6 \\
\hline 24 & & 62 & M & & & & NED, 132 \\
\hline 25 & & 72 & M & & & & NED, 40 \\
\hline 26 & & 76 & M & & & & NED, 24 \\
\hline 27 & & 54 & M & & & & Not mentioned \\
\hline 28 & Weinreb et al, 2006 (4) & 50 & $\mathrm{~F}$ & Parotid & 2.0 & Parotidectomy & NED, 5 \\
\hline 29 & & 73 & M & Parotid & 1.8 & $\begin{array}{l}\text { Parotidectomy } \\
\text { and supraomohyoid } \\
\text { neck dissection }\end{array}$ & NED, 60 \\
\hline 30 & & 67 & $\mathrm{~F}$ & Parotid & 2.5 & $\begin{array}{c}\text { Parotidectomy } \\
\text { and chemotherapy } \\
\text { and radiotion therapy }\end{array}$ & Not mentioned \\
\hline 31 & Arai et al, 2009 (5) & 32 & $\mathrm{~F}$ & Parotid & 2.8 & Parotidectomy & NED, 24 \\
\hline 32 & Laco et al, 2010 (9) & 50 & $\mathrm{~F}$ & Parotid & 1.5 & Enucleation of the tumor & NED, 24 \\
\hline 33 & Nakazawa et al, 2010 (10) & 56 & $\mathrm{~F}$ & Parotid & 3.0 & Parotidectomy & NED, 12 \\
\hline 34 & Kusafuka et al,2010 (11) & 38 & $\mathrm{~F}$ & Parotid & 3.5 & $\begin{array}{l}\text { Superficial lobectomy } \\
\text { of parotid gland }\end{array}$ & NED, 8 \\
\hline 35 & Weinreb et al, 2011 (12) & 59 & $\mathrm{~F}$ & Parotid & 3.5 & Not mentioned & Not mentioned \\
\hline 36 & Wang et al, 2013 (7) & 48 & M & Parotid & 2.0 & Parotidectomy & NED, 16 \\
\hline 37 & & 58 & $\mathrm{~F}$ & Parotid & 3.5 & Parotidectomy & NED, 7 \\
\hline 38 & Projetti F et al, 2014 (13) & 57 & M & Parotid & 2.7 & Not mentioned & Not mentioned \\
\hline 39 & Obokata A et al, 2013 (14) & 65 & M & Submandibular & 4.0 & Not mentioned & Notmentioned \\
\hline 40 & Present case & 56 & $\mathrm{~F}$ & Palate & 2.0 & resection of tumor & NED, 12 \\
\hline Mean & & 59.21 & $\begin{array}{c}23 \mathrm{~F}, 16 \mathrm{M}, \\
1 \mathrm{U}\end{array}$ & & & & \\
\hline
\end{tabular}

M, male; F, female; U, unknown; N/A, not available; NED, no evidence of disease. 
School of Dental Medicine) for correcting and editing the original manuscript. The authors also thank Mr. Noriaki Kasai and Mr. Kei Nishikori for providing encouragement.

\section{References}

1. Brandwein-Gensler MS and Gnepp DR: Low-grade cribriform cystadenocarcinoma. In: World Health Organization Classification of Tumours. Pathology and Genetics Head and Neck Tumors. Barnes L, Eveson JW, Reichart P and Sidransky D (eds). IARC Press, Lyon, p233, 2005.

2. Delgado R, Klimstra D and Albores-Saavedra J: Low grade salivary duct carcinoma. A distinctive variant with a low grade histology and a predominant intraductal growth pattern. Cancer 78: 958-967, 1996.

3. Brandwein-Gensler M, Hille J, Wang BY, Urken M, Gordon R, Wang LJ, Simpson JR, Simpson RH and Gnepp DR: Low-grade salivary duct carcinoma: Description of 16 cases. Am J Surg Pathol 28: 1040-1044, 2004.

4. Weinreb I, Tabanda-Lichauco R, Van der Kwast $\mathrm{T}$ and Perez-Ordoñez B: Low-grade intraductal carcinoma of salivary gland: Report of 3 cases with marked apocrine differentiation. Am J Surg Pathol 30: 1014-1021, 2006.

5. Arai A, Taki M, Mimaki S, Ueda M and Hori S: Low-grade cribriform cystadenocarcinoma of the parotid gland: A case report. Auris Nasus Larynx 36: 725-728, 2009.

6. Nakatsuka S, Harada H, Fujiyama H, Takeda K, Kitamura K, Kimura H, Nagano T, Ito M and Asada Y: An invasive adenocarcinoma of the accessory parotid gland: A rare example developing from a low-grade cribriform cystadenocarcinoma? Diagn Pathol 6: 122, 2011.

7. Wang L, Liu Y, Lin X, Zhang D, Li Q, Qiu X and Wang EH: Low-grade cribriform cystadenocarcinoma of salivary glands: Report of two cases and review of the literature. Diagn Pathol 8: 28, 2013.

8. Tatemoto Y, Ohno A and Osaki T: Low malignant intraductal carcinoma on the hard palate: A variant of salivary duct carcinoma? Eur J Cancer B Oral Oncol 32B: 275-277, 1996.

9. Laco J, Podhola M and Dolezalova H: Low-grade cribriform cystadenocarcinoma of the parotid gland: A neoplasm with favorable prognosis, distinct from salivary duct carcinoma. Int J Surg Pathol 18: 369-373, 2010.

10. Nakazawa T, Kondo T, Yuminomochi T, Nakazawa K, Ishii Y, Mochizuki K, Kawasaki T, Yamane T, Miyata M, Motosugi U and Katoh R.: Fine-needle aspiration biopsy of low-grade cribriform cystadenocarcinoma of the salivary gland. Diagn Cytopathol 39: 218-222, 2011.
11. Kusafuka K, Itoh H, Sugiyama C and Nakajima T: Low-grade salivary duct carcinoma of the parotid gland: Report of a case with immunohistochemical analysis. Med Mol Morphol 43: 178-184, 2010.

12. Weinreb I: Intraductal carcinoma of salivary gland (so-called low-grade cribriform cystadenocarcinoma) arising in an intraparotid lymph node. Head Neck Pathol 5: 321-325, 2011.

13. Projetti F, Lacroix-Triki M, Serrano E, Vergez S, Barres BH, Meilleroux J, Delisle MB and Uro-Coste E: A comparative immunohistochemistry study of diagnostic tools in salivary gland tumors: Usefulness of mammaglobin, gross cystic disease fluid protein 15, and p63 cytoplasmic staining for the diagnosis of mammary analog secretory carcinoma? J Oral Pathol Med 44: 244-251, 2014

14. Obokata A, Sakurai S, Hirato J, Sakamoto K, Takekoshi T and Aoki J: Cytologic features of low-grade cribriform cystadenocarcinoma of the submandibular gland: A case report. Acta Cytol 57: 207-212, 2013.

15. Foss RD, Ellis GL and Auclair PL: Salivary gland cystadenocarcinomas. A clinicopathologic study of 57 cases. Am J Surg Pathol 20: 1440-1447, 1996.

16. Takahashi H, Fujita S, Okabe H, Tsuda N and Tezuka F: Distribution of tissue markers in acinic cell carcinomas of salivary gland. Pathol Res Pract 188: 692-700, 1992.

17. Anderson C, Muller R, Piorkowski R, Knibbs DR and Vignoti P: Intraductal carcinoma of major salivary gland. Cancer 69: 609-614, 1992.

18. Eversole LR: Histogenic classification of salivary tumors. Arch Pathol 92: 433-443, 1971.

19. Regezi JA and Batsakis JG: Histogenesis of salivary gland neoplasms. Otolaryngol Clin North Am 10: 297-307, 1977.

20. Sato M, Hayashi Y, Yoshida H, Yanagawa T, Yura Y and Nitta T: Search for specific markers of neoplastic epithelial duct and myoepithelial cell lines established from human salivary gland and characterization of their growth in vitro. Cancer 54: 2959-2967, 1984.

21. Hayashi Y, Yanagawa T, Yoshida H, Yura Y, Nitta T and Sato M: Induction of other differentiation stages in neoplastic epithelial duct and myoepithelial cells from the human salivary gland grown in athymic nude mice. Cancer 55: 2575-2583, 1985.

22. Bahrami A, Perez-Ordonez B, Dalton JD and Weinreb I: An analysis of PLAG1 and HMGA2 rearrangements in salivary duct carcinoma and examination of the role of precursor lesions. Histopathology 63: 250-262, 2013. 